\title{
Economics of adult obesity and diabetes in Appalachia
}

\author{
Janaranjana Herath ${ }^{1^{*}}$, Cheryl Brown ${ }^{2}$, David Hill ${ }^{1}$ \\ ${ }^{1}$ Tillman School of Business, Mount Olive College, Mount Olive, USA; ${ }^{*}$ Corresponding Author: sbandara@moc.edu \\ ${ }^{2}$ Division of Resource Management, Davis College, West Virginia University, Morgantown, USA
}

Received 29 September 2013; revised 8 November 2013; accepted 25 November 2013

Copyright (C) 2013 Janaranjana Herath et al. This is an open access article distributed under the Creative Commons Attribution License, which permits unrestricted use, distribution, and reproduction in any medium, provided the original work is properly cited.

\begin{abstract}
Obesity and diabetes are major health problems in the United States. The primary aim of this stu$d y$ is to examine the association between obesity and diabetes and to estimate the cost of diabetes linked to obesity in the Appalachian region. A system of simultaneous equations approach, and a logit estimation are employed for the analyses. Behavioral Risk Factor Surveillance System (BRFSS) surveys for 2001 and 2009 are the main sources of data. Both county-level and individual-level data are used for the analyses. The simultaneous approach at county-level based on the changes of income, employment, obesity, and diabetes reveals that obesity increases diabetes, but diabetes does not have an effect on obesity. The counties with high initial levels of obesity had less obesity growth but more diabetes growth. Increasing income impacts negatively on diabetes growth. Logit analysis indicates that obesity significantly increases the risk of diabetes of adults' in Appalachia. Besides, being employed, higher income, as well as engaging in exercise reduce the prevalence of diabetes, while age increases diabetes. The economic cost of obesity-related diabetes is $\$ 1.9$ billion, and can be reduced through mitigating obesity.
\end{abstract}

Keywords: Appalachia; Diabetes; Logit Analysis; Obesity

\section{INTRODUCTION}

Obesity is a major health problem and nearly 34 percent of the US adult population are obese [1,2]. With the current trend of obesity, 50 percent of the US population will be obese in 2030 [3]. According to many studies, diabetes (type II), heart disease, hypertension, cancer, diabetes, asthma, and some psychological disorders link to obesity [4-6]. Obesity increases the risk of premature mortality [7] and is associated with nearly 300,000 annual deaths in the United States [5]. However, the magnitude of health impacts of a particular region depends upon the levels of obesity-related diseases, socioeconomic and behavioral characteristics of individuals [8,9], and environmental and geographical characteristics $[10,11]$.

The epidemic of obesity absorbs increasingly greater health care budgets in the United States. For instance, health expenditures (as a share of GDP) were 15.2 percent in 2003 [12]. There are four major categories of the economic impacts associated with obesity: direct medical costs, productivity costs, transportation costs, and human capital costs [13]. According to the US Department of Health and Human Services [14], the annual cost of obesity was $\$ 147$ billion in 2008 and people who were obese had annual medical costs that were $\$ 1429$ higher than the cost for people of normal body weight. The overall annual cost of being obese is $\$ 2646$ for an obese man and $\$ 4879$ for an obese woman [3].

The prevalence of diabetes (type II) continued to increase with obesity in the United States [15]. It requires a lifetime of medical care and drug therapy from the beginning in controlling diabetes (type II) which lowers quality of life. The economic costs attributable to obesity were $\$ 11.3$ billion for diabetes (type II) [16]. The childhood obesity shows a positive relationship with diabetes (type II) among children, especially between $10-17$ years old [17]. Thus, the main objectives of the study are to examine the association between obesity and diabetes and to estimate the cost of diabetes linked to obesity in Appalachia.

The paper spreads as follows. Section 2 provides background information of Appalachia. Section 3 explains 
methods and data sources. Section 4 discusses empirical results and analysis. Section 5 presents conclusions.

\section{THE APPALACHIAN REGION}

The Appalachian Region consists of 420 counties in 13 states. Ninety-six Appalachian counties are considered as "economically distressed," ninety counties are at "risk", and 219 have "transitional economies" [18]. The region is facing a lack of human, financial, and technical resources, and highly depends on mining, forestry, agriculture, chemical industries, professional service, and manufacturing [18]. The Appalachian region is home for nearly 24.8 million, and the highest population is reported from Northern Appalachia. The lowest population reports from Central Appalachia. The region is divided into five sub-regions as Northern, North Central, Central, South Central, and Southern [18]. The unemployment rates in two-thirds of Appalachian counties are higher than the national rate [18]. Moreover, the per capita personal income, average earnings, and per capita investment income are lower than the national averages. According to the economic assessment of Appalachia [19], educational levels within the region are low.

About 44 percent of the Appalachian population are obese and overweight [18]. Approximately, 10 percent over the population is suffering from diabetes, which may be related to obesity [20]. West Virginia, Tennessee, Kentucky, Mississippi, Louisiana, middle Alabama, South Georgia, and the coastal regions of North and South Carolina reports higher obesity and diabetes rates than the national average $[21,22]$. CDC further reveals that 81 percent of the counties in Kentucky, Tennessee, and West Virginia have the highest rates of diabetes and obesity. Meanwhile, 77 percent of the counties in Alabama, Georgia, Louisiana, Mississippi, and South Carolina report cases of diabetes and obesity. Counties on the "high end" of obesity prevalence are Dallas and Greene in Alabama, and Holmes, Humphreys and Jefferson in Mississippi. Counties that report a high prevalence of diseases, like diabetes, cancer, and heart disease are Greene, Lowndes and Perry in Alabama, and Holmes and Jefferson in Mississippi.

\section{METHODS AND DATA}

In order to examine the association between obesity and diabetes a set of linear simultaneous equations is used. Statistically this approach helps reach better comprehensive estimations. Within the consumer's utility maximization context, a Logit analysis is used to estimate the cost of diabetes linked to obesity. A Logit regression is a type of probabilistic classification model which is used for predicting the outcome of a categorical dependent variable based on predictor variables.

\subsection{Examine the Impacts of Obesity on Diabetes in Appalachia}

A system of simultaneous equations model is used to examine the impacts of obesity on diabetes. The model assumes the interdependence of income, employment, obesity, and diabetes within the context of consumer's utility theory. Interestingly, the simultaneous equations approach accounts for interactions among the interdependent variables, and make comprehensive estimations. Moreover, the estimations based on a system of equations overcome inconsistency and bias and lead to efficient estimation. The county average values of income, employment, obesity, and diabetes are used as interdependent variables in the model for the period of 2001 to 2009. All other exogenous variables of social factors (SF), behavioral factors (BF) and environmental factors (EF) are used at the county level for the same period. The model for the analysis is derived from the simultaneous equations approach of Deller et al. and Rosenberger et al. [23,24].

The variables Income $\left(I^{*}\right)$, Employment $\left(E^{*}\right)$, Obesity $\left(\mathrm{O}^{*}\right)$, and Diabetes $\left(\mathrm{D}^{*}\right)$ represent the long term equilibrium levels of income, employment, obesity, and diabetes. The $\Omega^{\mathrm{I}}, \Omega^{\mathrm{E}}, \Omega^{\mathrm{O}}$, and $\Omega^{\mathrm{D}}$ are a set of variables describing initial conditions that measure $\mathrm{SF}, \mathrm{EF}$, and $\mathrm{BF}$ related to obesity-linked diabetes implications. The general form of the model is as follows. $\left.\Omega^{\mathrm{I}}\right)$

(1) Income $^{*}=\mathrm{f}$ (Employment*, Obesity ${ }^{*}$, Diabetes*, $\left.\Omega^{\mathrm{E}}\right)$

(2) Employment ${ }^{*}=\mathrm{g}$ (Income*, Obesity ${ }^{*}$, Diabetes ${ }^{*}$, (3) Obesity ${ }^{*}=\mathrm{h}$ (Income ${ }^{*}$, Employment ${ }^{*}$, Diabetes ${ }^{*}$, $\Omega^{\mathrm{O}}$ ) $\left.\Omega^{\mathrm{D}}\right)$

(4) Diabetes ${ }^{*}=\mathrm{k}$ (Employment ${ }^{*}$ Income ${ }^{*}$, Obesity ${ }^{*}$,

Considering the equilibrium framework of the model, short-term adjustments of income $(\Delta \mathrm{I})$, employment $(\Delta \mathrm{E})$, obesity $(\Delta \mathrm{O})$, and diabetes $(\Delta \mathrm{D})$, to the long-term equilibriums of $\mathrm{I}^{*}, \mathrm{E}^{*}, \mathrm{O}^{*}$, and $\mathrm{D},{ }^{*}$ can be derived to the empirical analysis. Respectively, the changes of income, employment, obesity, and diabetes are given by $\Delta \mathrm{I}, \Delta \mathrm{E}$, $\Delta \mathrm{O}$, and $\Delta \mathrm{D} . \mathrm{I}_{\mathrm{t}-1}, \mathrm{E}_{\mathrm{t}-1}, \mathrm{O}_{\mathrm{t}-1}$ and $\mathrm{D}_{\mathrm{t}-1}$ are initial conditions of income, employment, obesity, and diabetes. The linear estimated parameters of initial conditions, changes of interdependent variables, and other $\mathrm{SF}, \mathrm{EF}$, and $\mathrm{BF}$ are given by $\beta, \mathrm{r}$ and $\delta . \alpha$ represents intercept values. The model captures structural relationships while simultaneously isolating the influence of obesity on diabetes.

(5) $\Delta \mathrm{I}=\alpha_{\mathrm{oI}}+\beta_{1 \mathrm{II}} \mathrm{I}_{\mathrm{t}-1}+\beta_{2 \mathrm{I}} \mathrm{E}_{\mathrm{t}-1}+\beta_{3 \mathrm{I}} \mathrm{O}_{\mathrm{t}-1}+\beta 4 \mathrm{ID}_{\mathrm{t}-1}+$ $\mathrm{r}_{11} \Delta \mathrm{E}+\mathrm{r}_{2 \mathrm{I}} \Delta \mathrm{O}+\mathrm{r}_{3 \mathrm{I}} \Delta \mathrm{D}+\sum \delta_{\mathrm{I}} \Omega^{\mathrm{I}}$

(6) $\Delta \mathrm{E}=\alpha_{\mathrm{oE}}+\beta_{1 \mathrm{E}} \mathrm{I}_{\mathrm{t}-1}+\beta_{2 \mathrm{E}} \mathrm{E}_{\mathrm{t}-1}+\beta_{3 \mathrm{E}} \mathrm{O}_{\mathrm{t}-1}+\beta_{4 \mathrm{ED}} \mathrm{D}_{\mathrm{t}-1}+$ $\mathrm{r}_{1 \mathrm{E}} \Delta \mathrm{I}+\mathrm{r}_{2 \mathrm{E}} \Delta \mathrm{O}+\mathrm{r}_{3 \mathrm{E}} \Delta \mathrm{D}+\sum \delta_{\mathrm{E}} \Omega^{\mathrm{E}}$

(7) $\Delta \mathrm{O}=\alpha_{\mathrm{oO}}+\beta_{1 \mathrm{O}} \mathrm{I}_{\mathrm{t}-1}+\beta_{2 \mathrm{O}} \mathrm{E}_{\mathrm{t}-1}+\beta_{3 \mathrm{O}} \mathrm{O}_{\mathrm{t}-1}+\beta_{4 \mathrm{I}} \mathrm{D}_{\mathrm{t}-1}+$ 
$\mathrm{r}_{11} \Delta \mathrm{I}+\mathrm{r}_{2 \mathrm{I}} \Delta \mathrm{E}+\mathrm{r}_{31} \Delta \mathrm{A}+\sum \delta_{\mathrm{O}} \Omega^{\mathrm{O}}$

(8) $\Delta \mathrm{D}=\alpha_{\mathrm{oI}}+\beta_{1 \mathrm{D}} \mathrm{I}_{\mathrm{t}-1}+\beta_{2 \mathrm{D}} \mathrm{E}_{\mathrm{t}-1}+\beta_{3 \mathrm{D}} \mathrm{O}_{\mathrm{t}-1}+\beta_{4 \mathrm{D}} \mathrm{D}_{\mathrm{t}-1}+$ $\mathrm{r}_{11} \Delta \mathrm{I}+\mathrm{r}_{21} \Delta \mathrm{E}+\mathrm{r}_{31} \Delta \mathrm{O}+\sum \delta_{\mathrm{D}} \Omega^{\mathrm{D}}$

\subsection{Estimate the Cost of Diabetes Linked to Obesity in Appalachia}

Within the consumer's utility maximization context, a Logit analysis is used to estimate the economic cost. Individual level data for diabetes and obesity for 2009 are used for the analysis. A Logit analysis of a response function for diabetes with obesity as a qualitative exogenous variable would give the coefficient for the marginal impact of obesity for diabetes. In a well-defined Logit equation, this coefficient for obesity indicates the contribution of obesity to diabetes. Multiplying the coefficient value by the known healthcare expenditures of diabetes, would give the cost of diabetes linked to obesity. These types of dose-response functions are used in cost calculations [25-27].

(9) $\mathrm{D}_{\mathrm{i}}=\mathrm{f}\left(\mathrm{O}_{\mathrm{i}}, \mathrm{SF}_{\mathrm{i}}, \mathrm{EF}_{\mathrm{i}}, \mathrm{BF}_{\mathrm{i}}\right)$

$D_{i}$ represents the diabetes of the $i^{\text {th }}$ individual, which appears as a qualitative dependent variable equal to one if the individual has diabetes and zero otherwise. $\mathrm{O}_{\mathrm{i}}$ is equal to one if the $\mathrm{i}^{\text {th }}$ individual is obese and zero otherwise. The variables of socioeconomic factors (SF), behavioral factors $(\mathrm{BF})$, and environmental factors $(\mathrm{EF})$ are specified for each individual.

The marginal effect of the estimated equation can be expressed as:

(10) $\mathrm{D}_{\mathrm{i}}=\alpha_{0}+\alpha_{1} \mathrm{O}_{\mathrm{i}}+\sum \psi \mathrm{SF}_{\mathrm{i}}+\sum \delta \mathrm{EF}_{\mathrm{i}}+\sum \omega \mathrm{BF}_{\mathrm{i}}$, where $\alpha_{0}$ indicates the intercept of the equation, $\alpha_{1}$, is the coefficient estimation for $\mathrm{O}_{\mathrm{i}}$. The summations of the coefficients of SF, EF, and $\mathrm{BF}$ are indicated by $\psi, \delta$, and $\omega$.

To obtain the total economic cost $\left(\mathrm{TEC}_{\mathrm{D}}\right)$ of obesity related to diabetes, the total expenditures on healthcare for diabetes $\left(\mathrm{THE}_{\mathrm{D}}\right)$ in Appalachia is multiplied by the coefficient of $\mathrm{O}_{\mathrm{i}}\left(\alpha_{1}\right)$ from the marginal effects of the Logit equation for diabetes. Nevertheless, any loss in productivity due to absenteeism, or the loss to an individual over his or her lifetime of lost income does not account for the total economic cost.

(11) $\mathrm{TEC}_{\mathrm{D}}=\mathrm{THE}_{\mathrm{D}} \times \alpha_{1}$

\subsection{Sources of Data}

Behavior Risk Factor Surveillance Systems (BRFSS) survey data collected by the Center for Disease Control and Prevention (CDC) for 2001 and 2009 [28,29] are the main source of data. For the analysis, both individuallevel and country averaged, data are used. County averaged data for 2001, and 2009 are used to examine the impacts of obesity on diabetes. Individual-level data of 2009 are used to estimate the cost of diabetes linked to obesity. BRFSS is a survey of health-risk behaviors in non-institutionalized civilian adults, age 18 years and over. Data are collected from a stratified random sample by the state health departments with the collaboration of the CDC. Moreover, data for the county-level employment, income, number of adults, and population, are collected from the Bureau of Economic Analysis, and the US Census Reports [30-32]. Analysis is done using the statistical package of STATA [33].

\section{RESULTS AND DISCUSSION}

\subsection{Examining the Impacts of Obesity on Diabetes in Appalachia}

Table 1 shows the county averaged variables, and their descriptions used to examine the link of obesity and diabetes. Table 2 shows the econometric results of the analysis.

A system of four simultaneous equations was used to measure the links between obesity and diabetes in Appalachia. The variables used, and the results are presented in Table 2. The first column of the table shows the exogenous variables used in each equation. Columns 2 and 3 indicate results for income change (INCC) equation, while columns 4 and 5 present results for employment change (EMPC). Results for the obesity change (OBEC) equation are shown in columns 6 and 7, and results for the diabetes change (DIAC) equation are presented in columns 8 and 9 .

The empirical results show that income change (INCC) is significantly and positively related to employment change (EMPC). Thus, when employment increases by a one-percent income increases by 0.4 percent in Appalachian counties. Obesity change (OBEC) is significantly and positively related to income change (INCC). Accordingly, when obesity change increases by a one-percent, income change increases by 0.2 percent. Age indicates a positive relationship with income change. A one-year increase in age, improves income growth by 0.08 percent. Initial values of income (INC01), and employment (EMP01) show significant results but impacts are minimal.

Results for employment change equation show that a one percent change in income growth increase employment growth by 0.33 percent. One reason for this could be that high income leads to more savings and investment which increases employment. Also, high income in a county may lead to improved educational facilities, healthcare facilities, and other local amenities that increase the number of jobs. Results further indicate that growth in diabetes rates (DIAC) has a negative relationship with employment growth. The initial level of diabetes (DIAB01) also has a negative relationship with employment growth. Thus, an increasing percentage of diabetic patients decrease employment growth in Appala- 
Table 1. Definitions of county-level variables used for the analysis, 2001 and 2009.

\begin{tabular}{|c|c|c|c|}
\hline Vari. & Description & Mean & Std. Dev. \\
\hline INC01 & Average annual household income, 2001 & $\$ 26,616$ & $\$ 5617$ \\
\hline EMP01 & Number of adults 18 and older who were employed, 2001 & 26,481 & 45,891 \\
\hline OBE01 & Percentage of obese adults 18 and older, 2001 & 23.7 & 3.5 \\
\hline DIA01 & Percentage of adults 18 and older with diabetes, 2001 & 8.1 & 4.6 \\
\hline INC09 & Average annual household income, 2009 & $\$ 37,460$ & $\$ 7849$ \\
\hline EMP09 & Number of adults 18 and older who were employed, 2009 & 26,091 & 45,176 \\
\hline OBE09 & Percentage of obese adults 18 and older, 2009 & 30.8 & 5.4 \\
\hline DAI09 & Percentage of adults 18 and older with diabetes, 2009 & 15.5 & 6.5 \\
\hline POP 09 & County population & 59,399 & 96,730 \\
\hline AGE09 & Average age of adults 18 and older & 54.9 & 4.5 \\
\hline MAR09 & Percentage of population that was married & 56.0 & 10.0 \\
\hline EDU09 & Percentage of population that has had some college, a college degree or has a professional or graduate degree & 44.2 & 12.3 \\
\hline MAL09 & Percentage of males & 36.8 & 8.7 \\
\hline SLP09 & Average number of sleepless days of an adult 18 and older, 2009 & 8.5 & 2.4 \\
\hline SMK09 & Percentage of county's population 18 and older who smoke, 2009 & 24.0 & 9.2 \\
\hline DNK09 & Percentage of county's population 18 and older, consume alcohol, 2009 & 30.7 & 16.6 \\
\hline GHH09 & Percentage of county's populations say that their health conditions are good & 71.6 & 12.6 \\
\hline NORTH & 1 if the county is in the northern regions of Appalachia; 0 otherwise & 35.5 & 47.9 \\
\hline
\end{tabular}

chia. The initial level of employment (EMP01) is significant and negative but the coefficient is small. Education (EDU) has a significant and positive relationship with employment growth. There is a significant and positive relationship between the percentage of a county's population that is married, and employment growth.

The empirical results for obesity change (OBEC) equation indicates that increasing income change (INCC) increases obesity change. Results also show that income in 2001 (INC01) has a positive relationship with obesity change. The significant and negative relationship with the initial obesity rate shows that county which had a high obesity level have lower obesity rates.

The results for diabetes change (DIAC) show that income change (INCC) and diabetes change are significantly and negatively related. When income growth increases by one percent, diabetes rates decrease by 1.1 percent. This may be due to greater attention to diabetes care with increasing county income. As expected, obesity increases are significantly and positively related to increases in diabetes. A one percent increase in obesity change, increases diabetes change by 0.8 percent. This result is supported by Gregg et al. who found a continuous increase of diabetes with increasing obesity in the United States [15]. The negative impact of the initial income level indicates that when average county income was higher in 2001, increases in the rates of diabetes were lower in those counties.

\subsection{Estimate the Cost of Diabetes Linked to Obesity in Appalachia}

\section{1) Logit Analysis for Diabetes}

Definitions of all variables used for Logit analysis are presented in Table 3 with mean, standard deviation, minimum, and maximum value. Individual-level data in 2009 were used for the analysis. Data were cleaned from individuals who were pregnant or who had any kind of missing data for exogenous variables. Thus, the sample size was 21,225 individuals for the Appalachia.

Table 4 shows the results for Logit analysis. According to the results most of the independent variables are significant and have the expected signs. Obesity is significantly and positively related to diabetes; an obese person is 11 percent more likely to become diabetic than a non-obese person. Diabetes and age show a positive relationship as expected. According to Mayo Foundation [34], getting older, increases one's vulnerability towards diabetes (type II), especially after 45 years of age.

Those who are employed show significantly lower 
Table 2. Econometric results for system of equations including change in diabetes (DIAC).

\begin{tabular}{|c|c|c|c|c|c|c|c|c|}
\hline \multirow{2}{*}{ Var. } & \multicolumn{2}{|c|}{ Income change } & \multicolumn{2}{|c|}{ Employment change } & \multicolumn{2}{|c|}{ Obesity change } & \multicolumn{2}{|c|}{ Diabetes change } \\
\hline & Coefficient & $\mathrm{P}>|\mathrm{Z}|$ & Coefficient & $\mathrm{P}>|\mathrm{Z}|$ & Coefficient & $\mathrm{P}>|\mathrm{Z}|$ & Coefficient & $\mathrm{P}>|\mathrm{Z}|$ \\
\hline INCC & & & $0.33449^{* * *}$ & 0.00 & $1.17347^{* *}$ & 0.04 & $-1.15299^{* *}$ & 0.02 \\
\hline EMPC & $0.41022^{* * *}$ & 0.00 & & & $0.00513^{* *}$ & 0.99 & 0.07031 & 0.88 \\
\hline OBEC & $0.19912^{* * *}$ & 0.00 & 0.02846 & 0.64 & & & $0.81553^{* * *}$ & 0.00 \\
\hline DIAC & -0.04215 & 0.43 & $-0.22660^{* * *}$ & 0.00 & 0.29984 & 0.58 & & \\
\hline INC01 & $-0.00001^{* * *}$ & 0.00 & -0.00010 & 0.37 & & & $-0.00001^{*}$ & 0.06 \\
\hline EMP01 & $0.00001^{*}$ & 0.06 & $-0.00001^{* * *}$ & 0.00 & 0.00010 & 0.47 & 0.00010 & 0.76 \\
\hline OBE01 & & & 0.08273 & 0.72 & $-1.89317^{* * *}$ & 0.00 & 1.29238 & 0.26 \\
\hline DIA01 & -0.05195 & 0.88 & $-1.57932^{* * *}$ & 0.00 & 1.80850 & 0.60 & $-6.09294^{* * *}$ & 0.00 \\
\hline AGE09 & $0.00841^{* * *}$ & 0.00 & & & -0.00245 & 0.89 & 0.02592 & \\
\hline EDU09 & -0.00028 & 0.68 & $0.00098^{* *}$ & 0.06 & & & & \\
\hline MAL09 & 0.00045 & 0.52 & & & -0.00241 & 0.20 & & 0.71 \\
\hline POP09 & & & $0.00001^{* * *}$ & 0.00 & & & & \\
\hline MAR09 & & & $0.00241^{* * *}$ & 0.01 & & & & \\
\hline GHH09 & & & & & 0.00246 & 0.74 & & \\
\hline REC09 & & & & & -0.00215 & 0.68 & & \\
\hline SMK09 & & & & & 0.00146 & 0.21 & -0.00035 & 0.83 \\
\hline DNK09 & & & & & -0.00142 & 0.33 & -0.00193 & 0.36 \\
\hline NORTH & & & $-0.02657^{* *}$ & 0.05 & & & & \\
\hline
\end{tabular}

Number of observations $=420 . \mathrm{R}^{2}$ values: $\mathrm{INCC}=0.84 ; \mathrm{EMPC}=0.40 ; \mathrm{OBEC}=0.10 ; \mathrm{DIABC}=0.57 . \mathrm{Chi}^{2}$ values: $\mathrm{INCC}=2715.95 ; \mathrm{EMPC}=119.70 ; \mathrm{OBEC}=$ 222.58 ; DIABC $=868.95 .{ }^{* * *},{ }^{* *},{ }^{*}$ are significant at $1 \%, 5 \%$ and $10 \%$ respectively.

Table 3. Definitions of variables in Logit analysis, 2009.

\begin{tabular}{|c|c|c|c|c|c|}
\hline Var. & Description and unit & Mean & Std. Dev. & Min & Max \\
\hline DIA & 1 if diabetic; 0 otherwise & 14.49 & 35.27 & 0 & 1 \\
\hline OBE & 1 if obese; 0 otherwise & 30.89 & 46.56 & 0 & 1 \\
\hline AGE & In years & 55.46 & 16.06 & 27 & 99 \\
\hline MAR & 1 if married; 0 otherwise & 56.68 & 49.55 & 0 & 1 \\
\hline EDU & 1 if some college or higher; 0 otherwise & 51.14 & 49.98 & 0 & 1 \\
\hline EMP & 1 if employed; 0 otherwise & 40.17 & 49.02 & 0 & 1 \\
\hline INC & Annual income in dollars & 40,774 & 24,815 & 5000 & 80,000 \\
\hline GEN & 1 if male; 0 if female & 38.21 & 48.59 & 0 & 1 \\
\hline RAC & 1 if white; 0 if race other than white & 90.41 & 29.44 & 0 & 1 \\
\hline SLP & Number of sleepless days in previous month & 8.50 & 10.55 & 0 & 15 \\
\hline EXE & Number of minutes engaged in physical activities for the previous week & 403.57 & 674.95 & 0 & 1092 \\
\hline DNK & 1 if drinks alcohol; 0 otherwise & 0.3375 & 0.4728 & 0 & 1 \\
\hline SMK & 1 if smokes; 0 otherwise & 0.2093 & 0.4068 & 0 & 1 \\
\hline
\end{tabular}


probabilities of getting diabetes. This may be due to better income, education, and other facilities, associated with greater employment opportunities. Even though the impact value is low, increasing income decreases the potential of becoming a diabetic. A significant and positive result for gender indicates that adult men are more vulnerable to diabetes than adult women. Variable for

Table 4. Logit regression results for diabetes: marginal effects.

\begin{tabular}{cccc}
\hline Var. & Marginal Effect & Std. Err & $\mathbf{P}>|\mathbf{z}|$ \\
\hline OBE & $0.10855^{* * *}$ & 0.0038 & 0.00 \\
AGE & $0.00268^{* * *}$ & 0.0001 & 0.00 \\
MAR & -0.00362 & 0.0043 & 0.40 \\
EDU & -0.00533 & 0.0042 & 0.20 \\
EMP & $-0.04043^{* * *}$ & 0.0049 & 0.00 \\
INC & $-0.00001^{* * *}$ & 0.0000 & 0.00 \\
GEN & $0.03434^{* * *}$ & 0.0041 & 0.00 \\
RAC & $-0.04061^{* * *}$ & 0.0058 & 0.00 \\
EXE & $-0.00002^{* * *}$ & 0.0000 & 0.00 \\
DNK & $-0.05757^{* * *}$ & 0.0048 & 0.00 \\
SMK & -0.00284 & 0.0053 & 0.59 \\
\hline
\end{tabular}

Number of Observations $=21,225$. LR $\operatorname{chi}^{2}(12)=2315.23 ;$ Prob $>\operatorname{chi}^{2}=$ 0.0000. Log likelihood $=-7494.72$; Pseudo $\mathrm{R}^{2}=0.1338 .{ }^{* * *},{ }^{* *},{ }^{*}$ are significant at $1 \%, 5 \%$ and $10 \%$ respectively. race indicates that the white individuals are less likely to get diabetes than the non-white individuals. Spending more time on physical exercise decreases the potential of becoming a diabetic. Drinking alcohol indicates a negative association with diabetes. The result is supported by certain studies [35,36].

2) Calculating Total Healthcare Expenditures for Diabetes $\left(T H E_{D}\right)$

The calculation of total healthcare expenditure for diabetes in Appalachia is based on the estimations of Milken Institute [37] that calculated treatment costs as well as costs of productivity lost. The Milken Institute projected costs for diabetes up to 2023 for each state using Medical Expenditure Panel Survey (MEPS), and National Household Education Survey (NHES) data, in 2003. The estimation for 2009 was used to calculate total healthcare expenditure for diabetes for the Appalachian region. The calculations are presented in Table 5. The first column shows the Appalachian states, and the second column shows total population in those states. The third column lists the total population in only the Appalachian counties of each state. The fourth column presents the cost of diabetes of each state according to the projections of the Milken Institute (2007) for 2009. The fifth column shows the cost of diabetes for the Appalachian counties of each state, which were calculated by multiplying the cost of diabetes for each state in column 3 , by percentage of population in the Appalachian counties of each state. Thus, the total healthcare expenditure

Table 5. Calculation of total healthcare expenditure for diabetes for the Appalachian region (\$billion), 2009.

\begin{tabular}{|c|c|c|c|c|}
\hline Appalachian states & Total population in state & $\begin{array}{l}\text { Total population in } \\
\text { Appalachian counties }\end{array}$ & $\begin{array}{l}\text { Cost of diabetes } \\
\text { (\$billion) }\end{array}$ & $\begin{array}{l}\text { Cost of diabetes for } \\
\text { Appalachia* (\$billion) }\end{array}$ \\
\hline Alabama & $4,779,736$ & $3,024,719$ & 3.39 & 2.15 \\
\hline Georgia & $9,687,653$ & $2,924,921$ & 6.04 & 1.82 \\
\hline Kentucky & $4,339,367$ & $1,194,500$ & 3.09 & 0.85 \\
\hline Maryland & $5,773,552$ & 247,997 & 3.33 & 0.14 \\
\hline Mississippi & $2,967,297$ & 623,260 & 2.77 & 0.58 \\
\hline New York & $19,378,102$ & $1,049,686$ & 13.72 & 0.74 \\
\hline North Carolina & $9,535,483$ & $1,662,282$ & 6.14 & 1.07 \\
\hline Ohio & $11,536,504$ & $2,013,203$ & 8.26 & 1.44 \\
\hline Pennsylvania & $12,702,379$ & $5,736,617$ & 9.64 & 4.35 \\
\hline South Carolina & $4,625,364$ & $1,167,523$ & 2.20 & 0.56 \\
\hline Tennessee & $6,346,105$ & $2,801,826$ & 4.89 & 2.16 \\
\hline Virginia & $8,001,024$ & 681,686 & 4.68 & 0.40 \\
\hline West Virginia & $1,819,777$ & $1,819,777$ & 1.56 & 1.56 \\
\hline \multicolumn{4}{|c|}{ Total cost of diabetes for Appalachia } & 17.83 \\
\hline
\end{tabular}

${ }^{*}$ Calculated by authors Sources: US Census Bureau (2010) and Milken Institute (2007). 
for diabetes for Appalachia is $\$ 17.8$ billion. As the percentage of young people (less than 18 years) having diabetes is less than one percent $(0.26)$, the total calculated expenditure is assumed to be the total healthcare expenditure for diabetes of adults in Appalachia.

\section{3) Calculating Economic Cost of Diabetes Linked to} Obesity $\left(T E C_{D}\right)$

To obtain the total economic cost $\left(\mathrm{TEC}_{\mathrm{D}}\right)$ of diabetes linked to obesity, the total healthcare expenditures for diabetes ( $\$ 17.8$ billion) is multiplied by the coefficient of obesity $(0.10855)$, which was estimated using marginal effects from Logit analysis. Thus, the total economic cost of diabetes due to obesity is $\$ 1.934$ billion for 2009 in Appalachia. In other words, if obesity could be controlled completely the cost of diabetes would be reduced by up to $\$ 1.934$ billion for 2009 .

4) Estimating Reductions in Economic Cost of Diabetes Linked to Obesity $\left(T_{E C_{D}}\right)$ Associated with Reductions in Obesity of Individuals

To measure reduction of economic costs with reductions in obesity of individuals, estimations of total economic cost of obesity-related diabetes $\left(\mathrm{TEC}_{\mathrm{D}}\right)$ is used with the obesity rate for Appalachia in 2009 (31 percent). The intention is to estimate economic cost reductions that would occur with significant reductions in obesity from 31 percent. Reduction possibilities in total economic cost are considered by comparing obesity rates in Appalachia to three values. First, the potential economic gains in the region are calculated compared to Colorado, which reports the lowest obesity rate of 21 percent. Second, potential gains are estimated compared to the national average obesity rate in 2009 , which was 25 percent. Third, gains are estimated compared to the federal target of reducing obesity to 15 percent.

The potential gains are shown in Table 6. These estimations are conservative as all the costs of obesity-related diseases don't account for in these calculations. Also, it is assumed that reductions in costs are linearly related to reductions in obesity rates as actual impacts are not known. Thus, interpretation of these values should be done carefully.

Table 6. Total economic costs of obesity-related diabetes $\left(\mathrm{TEC}_{\mathrm{D}}\right)$ at different obesity rates $2009^{*}$.

\begin{tabular}{cc}
\hline TEC $_{\mathbf{D}}$ & \$million \\
\hline Current $\mathrm{TEC}_{\mathrm{D}}$ with $31 \%$ obesity rate & 1934.12 \\
TEC $_{\mathrm{D}}$ with $21 \%$ obesity rate (reduced to the Colorado level) & 1310.21 \\
$\begin{array}{cc}\mathrm{TEC}_{\mathrm{D}} \text { with } 25 \% \text { obesity rate } \\
\text { (reduced to the current national level) }\end{array}$ & 1559.77 \\
TEC $_{\mathrm{D}}$ with $15 \%$ obesity rate (reduced to the federal target) & 935.86 \\
\hline${ }^{*}$ Calculated by author. &
\end{tabular}

\section{CONCLUSIONS AND SUGGESTIONS}

The main purpose of this study was to examine the association between obesity and diabetes and to estimate the cost of diabetes linked to obesity in the Appalachian region. County-level analysis based on the changes of income, employment, obesity, and diabetes highlights a few important points. First, the analysis reveals that obesity and income changes are positively related in the Appalachian region. This occurs because income levels as well as obesity rates have been increasing within the last one to two decades in Appalachia [18]. Interestingly, county level analysis suggests that obesity increases diabetes, but diabetes does not affect obesity. Counties with high initial levels of obesity had less obesity growth but more diabetes growth. Increasing income impacts negatively on diabetes growth. This means that obesity needs to be controlled in order to control diabetes.

The county level results are supported by the individual level Logit analysis, which indicates that obesity significantly increases the risk of diabetes of adults' in Appalachia. Also, being employed, higher income, as well as engaging in exercise reduce the prevalence of diabetes, while age increases diabetes. The economic cost calculation shows that nearly $\$ 1.9$ billion of the cost of diabetes is due to obesity. Thus, policies to control diabetes need adequate attention of obesity reduction. Policy attempts on mitigating obesity with achievable targets can significantly reduce cost of diabetes in Appalachia.

\section{ACKNOWLEDGEMENTS}

The research was supported by funds appropriated to the Tillman School of Business, Mount Olive College.

\section{REFERENCES}

[1] Sabate, J. and Wien, M. (2010) Vegetarian diets and childhood obesity prevention. American Journal of Clinical Nutrition, 9, 1525s-1529s. http://dx.doi.org/10.3945/ajen.2010.28701F

[2] Finkelstein, E., Trogdon, J., Cohen, J.W. and Dietz, W. (2009) Annual medical spending attributable to obesity: Payer and service-specific estimates. Health Affairs, 28, 822-831. http://dx.doi.org/10.1377/hlthaff.28.5.w822

[3] Dor, A., Ferguson, C., Langwith, C. and Tan, E. (2010) A heavy burden: The individual costs of being overweight and obese in the United States. Research Report. Department of Health Policy, School of Public Health and Health Services, The George Washington University.

[4] Sturm, R., Ringel, J.S. and Andreyeve, T. (2004) Increasing obesity rates and disability trends. Health Affairs, 23, 199-205. http://dx.doi.org/10.1377/hlthaff.23.2.199

[5] Malnick, S.D.H. and Knobler, H. (2006) The medical complications of obesity. QJM: An International Journal of Medicine, 99, 565-579. 
http://dx.doi.org/10.1093/qjmed/hcl085

[6] Miljkovic, D. and Nganje, W. (2008) Regional obesity determinants in the United States: A model of myopic addictive behavior in food consumption. Agricultural Economics, 38, 375-384. http://dx.doi.org/10.1111/j.1574-0862.2008.00307.x

[7] World Health Organization. Risk Factor Projects (2005) Overweight and obesity.

http://www.who.int/mediacentre/news/releases/2005/pr44 len/index.html

[8] Cawley, J., Meyerhoefer, C. and Newhouse, D. (2005) The impacts of state physical education requirements on youth physical activity and overweight. NBER Working Paper 11411.

[9] Sacerdote, B. (2007) How large are the effects from changes in family environment? A study of Korean American adoptees. Quarterly Journal of Economics, 122, 119-158. http://dx.doi.org/10.1162/qjec.122.1.119

[10] Inagmi, S., Cohen, D.A., Finch, B.K. and Asch, S.M. (2006) You are where you shop: Grocery store locations, weight and neighborhoods. American Journal of Preventive Medicine, 31, 10-17. http://dx.doi.org/10.1016/j.amepre.2006.03.019

[11] Wang, M.C., Kim, S., Gonzalez, A.A., Macleod, K.E. and Winkleby, M.A. (2007) Socioeconomic and food related physical characteristics of the neighborhood environment are associated with body mass index. Journal of Epidemiology Community Health, 6, 491-498. http://dx.doi.org/10.1136/jech.2006.051680

[12] Hagist, C. and Kotlikoff, L.J. (2009) Who's going broke? Comparing growth in public healthcare expenditures in ten OECD Countries. Hacienda Pública Española, IEF, 188, 55-72.

[13] Hammond, R.A. and Levine, R. (2010) The economic impacts of obesity in the United States: Diabetes, metabolic syndrome and obesity. Targets and Therapy, 3, 285295.

[14] US Department of Health and Human Services (2010) The surgeon general call to action to prevent and decrease overweight and obesity. US Department of Health and Human Services, Office of Surgeon General, Rockville.

[15] Gregg, E.W., Cheng, Y.J., Cadwell, B.L., Imperatore, G., Williams, D.E., Flegal, K.M. and Williamson, D.F. (2005) Secular trends in cardiovascular disease risk factors according to body mass index in US adults. Journal of American Medical Association, 293, 1868-1874. http://dx.doi.org/10.1001/jama.293.15.1868

[16] Colditz, G.A. (1992) Economic costs of obesity. American Journal of Clinical Nutrition, 55, 503s-507s.

[17] Kumanyika, S.K., Obarzanek, E., Stettler, N., Bell, R., Field, A.E., Formann, S.P., Franklin, B.A., Gillman, M.W., Lewis, C.E., Poston II, W.C., Stevens, J. and Hong, Y. (2008) Population based prevention of obesity: The need for comprehensive promotion of healthful eating, physical activity, and energy balance. Circulation, 118, 428464.

http://dx.doi.org/10.1161/CIRCULATIONAHA.108.1897 $\underline{02}$
[18] Appalachian Regional Commission [ARC] (2011) Economic overview of Appalachia 2011.

http://www.arc.gov/images/appregion/Sept2011/Economi cOverviewSept2011.pdf

[19] Appalachian Regional Commission [ARC] (2010) Economic assessment of Appalachia. An Appalachian development initiative report.

http://www.arc.gov/images/programs/ardi/EconomicAsse ssmentofAppalachiaJune2010.pdf

[20] Wewers, M.R., Katz, M., Paskett, E.D. and Fickle, D. (2006) Risky behaviors among Ohio Appalachian adults. Preventive Chronic Disease, 3, A127.

[21] Centers for Disease Control and Prevention [CDC] (2009) Behavioral risk factor surveillance system survey data. US Department of Health and Human Services, Atlanta, Georgia.

[22] Centers for Disease Control and Prevention [CDC] (2009) Estimated county-level prevalence of diabetes and obesity-United States, 2007. Morbidity and Mortality Weekly Report, 58. http://www.cdc.gov/mmwr/PDF/wk/mm5845.pdf

[23] Deller, S.C., Tsung-Hsiu, T., Marcouiller, D.W. and English, D.B.K. (2001) The role of amenities and quality of life in rural economic growth. American Journal of Agricultural Economics, 83, 352-365. http://dx.doi.org/10.1111/0002-9092.00161

[24] Rosenberger, R.S., Sneh, Y. and Gurvitch, R. (2005) A spatial analysis of linkages between healthcare expenditures, physical inactivity, obesity and recreational supply. Journal of Leisure Research, 2005.

[25] Quah, E. and Boon, T. L. (2002) The economic cost of particulate air pollution on health in Singapore. Journal of Asian Economics, 14, 73-90. http://dx.doi.org/10.1016/S1049-0078(02)00240-3

[26] Lvovsky, K. (1998) Economic cost of air pollution with Special Reference to India, South Asia Environment Unit, World Bank, Washington DC.

[27] Ostro, B. (1995) Fine particulate air pollution and mortality in two southern California counties. Environmental Research, 70, 98-104. http://dx.doi.org/10.1006/enrs.1995.1053

[28] Centers for Disease Control and Prevention (CDC) Behavioral risk factor surveillance system survey data. US Department of Health and Human Services, Atlanta.

[29] Centers for Disease Control and Prevention [CDC] (2009) Behavioral risk factor surveillance system survey data. US Department of Health and Human Services, Atlanta.

[30] Bureau of Economic Analysis [BEA] (2009) Regional economic accounts. http://www.bea.gov/regional/gdpmap/GDPMap.aspx

[31] US Census Bureau (2000) Summary File 1 (SF 1) 100percent data. http://www.census.gov/census2000/sumfile1.html

[32] US Census Bureau (2010) State and county quick facts. http://quickfacts.census.gov/qfd/states/54000.html

[33] (1995) STATA 9.0. Statistical/Data Analysis. StataCorp, College Station. http://www.stata.com 
[34] Mayo Clinic (2011) Type two diabetes, risk factors. http://www.mayoclinic.com/health/type-2-diabetes/DS00 $\underline{585 / \mathrm{DSECTION}=\text { risk-factors }}$

[35] Eliasson, B. (2003) Cigarette smoking and diabetes. Progress in Cardiovascular Diseases, 45, 405-413.

[36] Carlsson, S., Hammar, N. and Grill, V. (2005) Alcohol consumption and type 2 diabetes. Meta-analysis of epi- demiological studies indicates a U-shaped relationship. Diabetologia, 48, 1051-1054.

http://dx.doi.org/10.1007/s00125-005-1768-5

[37] Milken Institute (2007) An unhealthy America: Economic burden of chronic disease.

http://www.chronicdiseaseimpact.com/ebcd.taf?cat=disea se 